\title{
Gigantes en la historia
}

\section{William Rojas G.}

Especialista en Medicina Interna y Endocrinología Universidad del Rosario, Jefe Servicio de Endocrinología Hospital de San José y Profesor Asociado Fundación Universitaria de Ciencias de la Salud

$\mathrm{L}$ a acromegalia y el gigantismo hipofisiario son entidades de muy baja prevalencia pero a pesar de esto es sorprendente que en la historia de la humanidad hay en todas las épocas, descripciones de casos, sobre todo de gigantismo, que nos muestran que es una entidad que siempre nos ha acompañado.

Si revisamos desde cuando existen documentos o relatos sobre la existencia de gigantes, la sorpresa es que están descritos desde los relatos de la Biblia. Según las referencias que aparecen en los libros del Antiguo Testamento, en el Génesis (Génesis 6,1-2) y en el Deuteronomio (Deuteronomio 13,11) se hace referencia a la existencia de gigantes como una raza de seres nacidos de la unión entre hermosas mujeres y ángeles de Dios y se denominan nephilims. Al parecer, parte de la justificación bíblica para el diluvio universal fue que Dios quería acabar con esta raza de gigantes debido a sus orígenes y a sus comportamientos. Posteriormente, otra descripción bíblica que hace referencia a los gigantes es cuando al llegar los israelitas a la tierra de Canaan envían a un grupo por adelantado para observar el tipo de pobladores que había en estas tierras y al regresar estos exploradores relatan la presencia de gigantes que habitan las tierras de Canaan. A pesar de su presencia, los israelitas deciden invadir estos territorios con la convicción de que Dios está con ellos y no permitirá que nada le suceda a su pueblo.

Otra referencia de la presencia de gigantes en la Biblia está en la descripción del rey Org, quien al parecer era un gigante debido a que su cama medía 5 metros de largo por 2 metros de ancho. Y más cercano a esto es la descripción de la pelea entre David y el último de los nephilim, Goliath, un guerrero que medía 2,8 metros de alto.

Si nos vamos a Oriente, el primer relato en donde se puede asumir la existencia de gigantes se encuentra en la Epopeya de Gilgamesh, escrita en el año 1200 a. C. en la que éste es un rey del cual se decía que medía en codos lo equivalente a 5,6 m de altura, lo que le permitía su arrogancia y comportamiento dominante ${ }^{(1)}$.

En la mitología griega son celebres las descripciones de gigantes en La Odisea, con los relatos de los cíclopes dentro de los cuales está Polifemo, y la existencia de los Titanes, dentro de los cuales Prometeo es el más famoso.

Con un poco de mezcla entre leyenda y lo que se ha podido encontrar en las excavaciones del antiguo Egipto, el faraón que más se menciona como exponente de acromegalia o gigantismo es Akhenaton I, conocido también como Neferjeperura Amenhotep, Ajenatón, Amenhotep IV o Amenofis IV, fue el décimo faraón de la dinastía XVIII de Egipto. Su reinado fue durante el periodo de 1353-1336 a. C. y perteneció al periodo denominado Nuevo Egipto. A pesar de que Akhenaton tuvo descendencia, todos los libros que hablan sobre acromegalia y gigantismo lo incluyen como un posible caso debido a que las imágenes encontradas sobre él, siempre mostraban una estatura mayor a la de sus congéneres y había desproporción entre su mentón, el tamaño de sus manos y sus pies. Sin embargo, un artículo publicado en la revista Internatiomal Journal of Dermatology describe la enfermedad de Akhenaton como una forma cefalotorácica del síndrome de lipodistrofia progresiva, basándose en la cara alargada con atrofia de la grasa facial, y el patrón corporal de distribución grasa que se ha encontrado en estatuas y bustos de este soberano ${ }^{(2)}$.

América no ha sido ajena a estos relatos sobre historias de gigantes. Juan de Torquemada (1615), sostuvo que los primeros habitantes de América habrían sido gigantes y por esto el hallazgo de grandes construcciones y monumentos en la América recién descubierta. También se suman a estos relatos de indígenas gigantes que habitaban lo que hoy corresponde a la Patagonia. En la Nueva Granada también hubo cierto interés por estas historias y se dice que Eloy de Valenzuela, subdirector de la Expedición Botánica tenía en su colección privada múltiples objetos de las culturas indígenas de la Nueva Granada y dentro de estos tenía algunos huesos que provenían del campo de gigantes de Soacha. En 1792 el virrey Ezpeleta, envió a la corte del rey Carlos IV muestras representativas de los pueblos de la Nueva Granada y dentro de lo enviado estaba como emisario el señor Pedro Antonio Cano, un campesino de la jurisdicción de Vélez, Santander, de 21 años, que medía 7 pies 5 pulgadas (aproximadamente 2,20 m). Este hecho generó gran revuelo en España y en América y llegó a ser publicado en los periódicos de la época, Papel Periódico de Santafé de Bogotá y en El Mercurio Peruano y ratificó la creencia de que en América existían gigantes. Su presencia dentro de listados de algunos gigantes famosos es referida en el libro Atlas of Cli- 
Tabla 1. Datos de algunos de los gigantes más antiguos

\begin{tabular}{l|c|c|c}
\multicolumn{1}{c|}{ Nombre } & Año reporte & Edad & Altura \\
\hline $\begin{array}{l}\text { Gigante irlandés } \\
\text { (Edmund Malloon) }\end{array}$ & 1698 & 19 & 228,5 \\
\hline $\begin{array}{l}\text { Gigante irlandés } \\
\text { (Gharles Byrne) }\end{array}$ & 1782 & 21 & $253 \mathrm{~cm}$ \\
\hline $\begin{array}{l}\text { Gigante peruano } \\
\text { (Pedro A Cani) }\end{array}$ & 1794 & 21 & $226 \mathrm{~cm}$ \\
\hline $\begin{array}{l}\text { Gigante Napolitano } \\
\text { Gigante bávaro } \\
\text { (Thomas Hasler) }\end{array}$ & 1871 & 18 & $215 \mathrm{~cm}$ \\
\hline $\begin{array}{l}\text { Gigante de } \\
\text { pomerania }\end{array}$ & 1878 & 25 & $227 \mathrm{~cm}$ \\
\hline \begin{tabular}{l} 
Lewis Wilkins \\
\hline
\end{tabular}
\end{tabular}

Modificada de Lisser H, Escamilla R, Atlas of Clinical Endocrinology. Ed Mosby Company St Louis 1957, pag 28 (Es de anotar que en la tabla se incluye a Pedro Cani, como el gigante peruano pero cuyo nombre correcto era Pedro Antonio Cano, de Velez, Santander, Colombia)

nical Endocrinology en donde se refieren a él como el gigante peruano, Pedro Cani (tabla 1). Posteriores investigaciones particularmente del denominado Campo de Gigantes de Soacha permitieron aclarar que los huesos encontrados no eran humanos sino correspondían a animales prehistóricos de la familia de los mastodontes ${ }^{(3)}$.

Lamentablemente, de todos los relatos anteriores no existe ninguna evidencia física de la presencia del gigantismo o la acromegalia en la historia del hombre. Las primeras evidencias sobre la existencia de humanos con gigantismo o acromegalia nos vienen de hallazgos arqueológicos en Grecia y Roma. En Grecia, hacia 1985, unas excavaciones en la meseta central de la acrópolis de Eleutherna permitieron el hallazgo de unos restos óseos de una persona de sexo no determinado, de aproximadamente entre 25 y 35 años, correspondientes al siglo VII a. C. en los que se pudo evidenciar, por el grosor de la corteza de los huesos y los cambios en los fragmentos de huesos del cráneo, silla turca parcial, la presencia de erosión y ensanchamiento sugestivos de un tumor hipofisiario y que sumados a los cambios óseos en otros huesos largos sugieren la presencia de acromegalia $^{(4)}$. Otro hallazgo, esta vez en Roma, fue publicado en la revista Journal of Clinical Endocrinology and Metabolism de 2012, indica que durante excavaciones en la acrópolis de la torre serpentana, correspondiente a la Roma Imperial, siglo III a. C. se encontró un esqueleto completo correspondiente a un hombre de aproximadamente 16 a 20 años de edad, cuya estatura calculada fue de $202 \mathrm{~cm}$. Algunos huesos mostraban aún la evidencia de la existencia de cartílago de crecimiento al momento de la muerte, lo que hace pensar además que este hombre sufría de hipogonadismo o, al menos, tenía retardo en el cierre de los cartílagos de crecimiento $^{(5)}$. Con este hallazgo se pudo, por lo tanto, evidenciar que era posible la presencia de acromegalia o gigantismo en la Roma Antigua, lo que da más validez a los relatos sobre Maximus Trax, emperador 235 años a. C. descrito en la literatura como una montaña humana, y las descripciones del emperador Ptolomeo I Soter, quien por las imágenes en las monedas acuñadas en la época presentaba un prognatismo y cambios faciales sugestivos de acromegalia, que se observaron posteriormente en algunos de sus descendientes, lo que haría pensar en una acromegalia familiar.

Si nos mantenemos por la línea de figuras del gobierno, encontramos ya en época más reciente la descripción de un soberano desproporcionadamente más alto que los restantes miembros de la corte española, con prognatismo, mala implantación dental, manos y pies grandes, e infertilidad. Gobernó entre 1454 y 1474 y murió de una hemorragia digestiva. Para dar más crédito a los relatos, sus restos fueron analizados por el Dr. Gregorio Marañón, quien llegó a la conclusión de que pertenecían a un eunucoide acromegálico. Se trataba de Enrique IV, conocido como El Impotente ${ }^{(6)}$. Del mismo modo, en la corte francesa de finales del siglo XV se encuentra la descripción de Francisco I como un soberano que medía más de 2 metros, tenía extremidades desproporcionadamente largas que terminaban en manos y pies grandes, nariz larga y mentón prominente, rasgos que eran difíciles de disimular por los pintores de la época ${ }^{(7)}$. Más cerca a nuestros días, encontramos una publicación de Pituitary de 2010 en donde se describe el proceso de cambios en su fisonomía que tuvo el gobernador de Baja California Pío de Jesús Pico, último gobernador mexicano de estos territorios a finales del siglo XVIII. La foto (figura 1) muestra que, durante una época de su vida, tuvo cambios característicos de acromegalia, y que al parecer asociado a un cuadro de cefalea intensa, dichos cambios se estabilizaron y se resolvieron, llegando a fallecer a los 89 años de causas naturales $^{(8)}$.

En el arte, una forma indirecta de expresar las vivencias cotidianas, también vemos la presencia de figuras humanas con acromegalia y gigantismo.

En el lejano Oriente se encuentra un bajorrelieve indio del siglo II a. C. que muestra la imagen de un hombre con acromegalia a quien le están quitando un diente con la ayuda y fuerza de un elefante ${ }^{(9)}$.

Entre las ruinas de los mayas se encontró un bajorrelieve en el que se muestra la imagen de un hombre que está vestido con atuendos típicos y a quien en su fisonomía resaltan los arcos superciliares prominentes, dientes separados y prognatismo, aspectos que no son vistos en la mayoría de las imágenes y pinturas de estos pueblos ${ }^{(10)}$.

Tal vez las obras de arte más famosas sobre la fisonomía en la acromegalia están trabajadas por Michelangelo Caravaggio, quien en tres pinturas diferentes sobre la victoria de David 
Figura 1. Cambiso evidentes de acromegalia en manos y cara de Pío de Jesús Pico, gobernador de Baja California

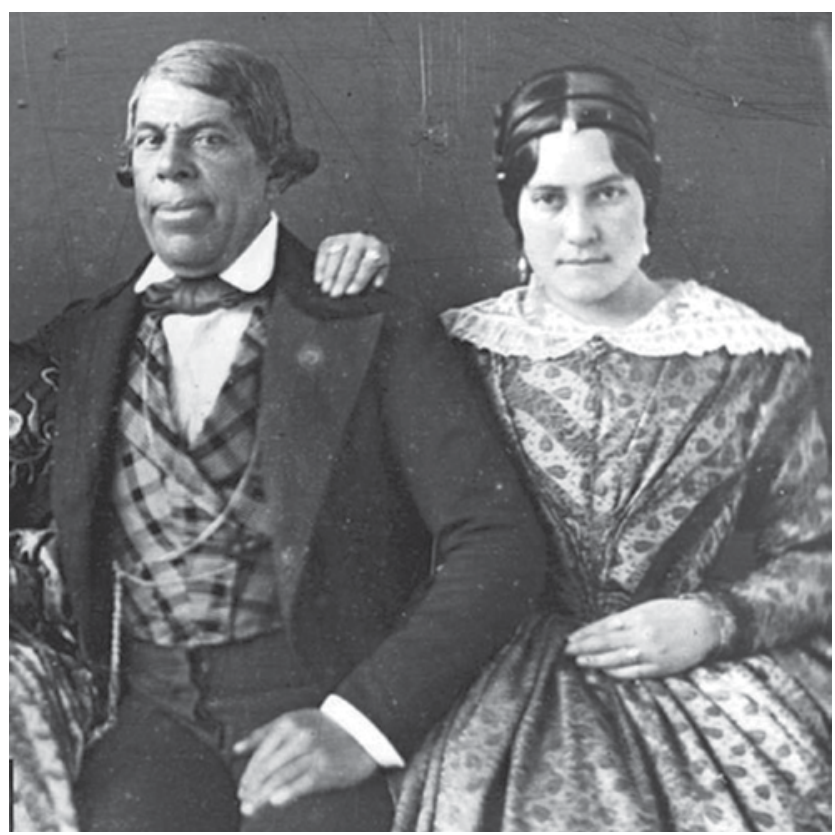

Tomado de Login I., Login J., Governor Pio Pico, the monster of California... no more: lessons in neuroendocrinology. Pituitary 2010;13: 80-86

sobre Goliath (1599, 1607 y 1610) plasmó en la cabeza de Goliath las características típicas del paciente acromegálico. Lo interesante de su obra es que se supone que el personaje que sirvió de modelo para pintar la imagen de David era Francesco Boneri, posiblemente su amante, y se cree que la imagen correspondiente a Goliath era un autorretrato, de donde surge entonces la idea de que Caravaggio tenía acromegalia ${ }^{(11)}$.

El pintor Paul Serousier, de la corriente posimpresionista plasmó en su obra Louise ou la servante Bretonne (figura 2) todas las características de una mujer con acromegalia, cuatro años después de la descripción de la enfermedad por Pierre Marie ${ }^{(12)}$. Y en época más reciente, Pablo Picasso, creador del movimiento pictórico Cubismo, pintó la obra Mujer sentada, en 1920 y sorprende ver todos los rasgos de acromegalia que tenía esta mujer, manos y pies grandes, atribuibles al movimiento pictórico, pero además su cara también mostraba prognatismo $^{(13)}$.

Finalmente, es importante resaltar las publicaciones que sobre acromegalia han salido de la experiencia médica colombiana. La primera descripción en la época moderna sobre una paciente con acromegalia fue publicada en 1935 en la revista del Instituto Nacional de Radium, posterior Instituto Nacional de Cancerología (figura 3). En este reporte se presenta el caso de una mujer de 25 años con todo el cuadro clínico de acromegalia, quien fue sometida a una trepanación de cráneo para extirpación de hipófisis, pero lamentablemente falleció en el posoperatorio ${ }^{(14)}$. Siete años después encontramos la publicación en la revista $R e$ -
Figura 2. Nótese el tamaño de las manos y el mentón prominente en esta pintura de Paul Serusier

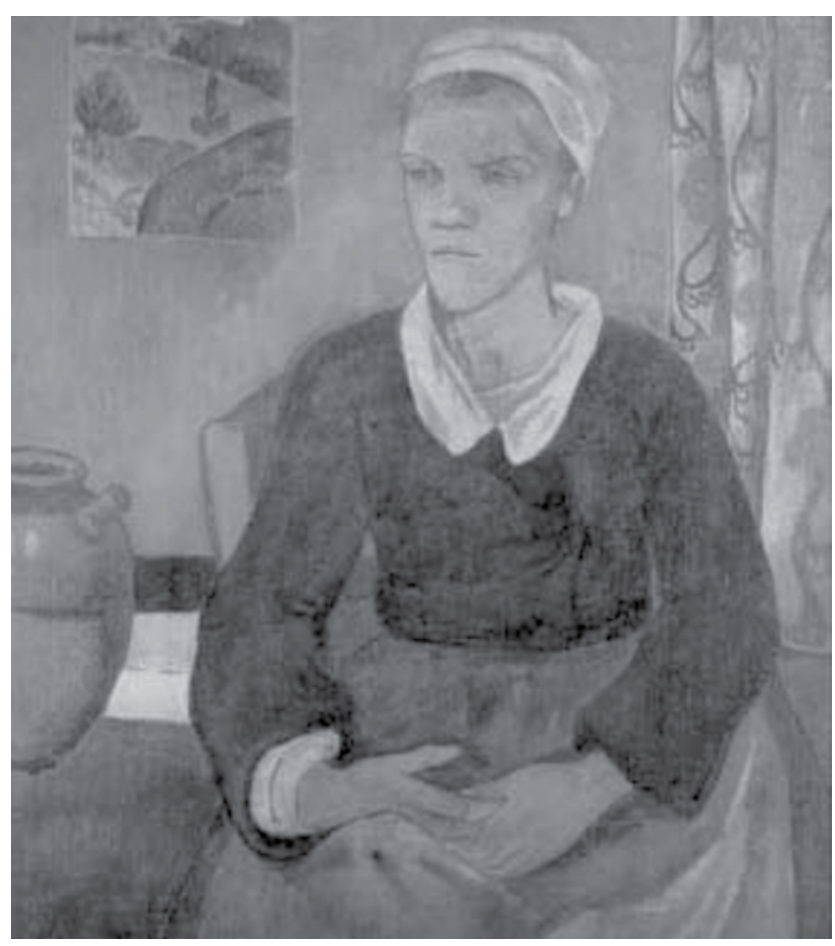

Tomado de Pozzilli P Leslie D, Endocrinology and Art, Louise Ou La servante Bretonne J. Endocrinol. Invest. 2003; 26: 1051

Figura 3. Características fenotípicas de acromegalia en la paciente del Instituto Nacional de Radium

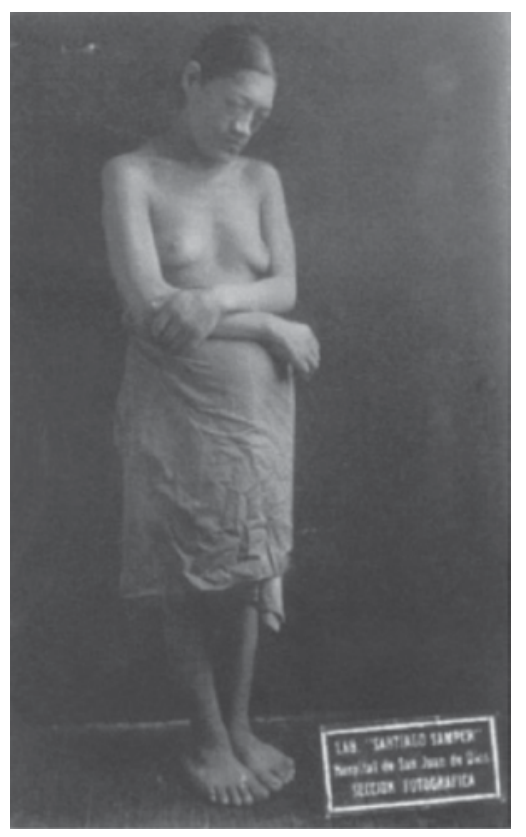

Tomado de Barbosa G, Wiesner C., Garavito G., Un Caso de acromegalia en el Instituto Nacional de Radium (1935) Revista Colombiana de Cancerologia 2004; 8(2): 52-56. 
pertorios de Medicina y Cirugía del Hospital de San José donde el Dr. Laurentino Muñoz hace la descripción de un paciente con acromegalia procedente de Zipaquirá (figura 4) ${ }^{(15)}$.

Hay en el mundo personas que se han dedicado a la búsqueda de información sobre la presencia de gigantes y dentro del cuerpo médico posiblemente el Dr. Wouter W. de Herder es una de ellas. Ha escrito múltiples artículos sobre los gigantes en la literatura médica y es quien hace las mejores descripciones de los gigantes importantes en la literatura médica, incluyendo a Robert Pershing Wadlow, conocido como el gigante de Alton, quien nació en 1918 y murió en 1940, con su estatura de 272 cm era, posiblemente, el ser humano más alto de la historia reciente (figura 7) ${ }^{(16)}$. Con la colaboración de Jean Périé y Arjen

Figura 4. Paciente con acromegalia presentado por el Dr. Laurentino Muñoz en el Hospital de San José

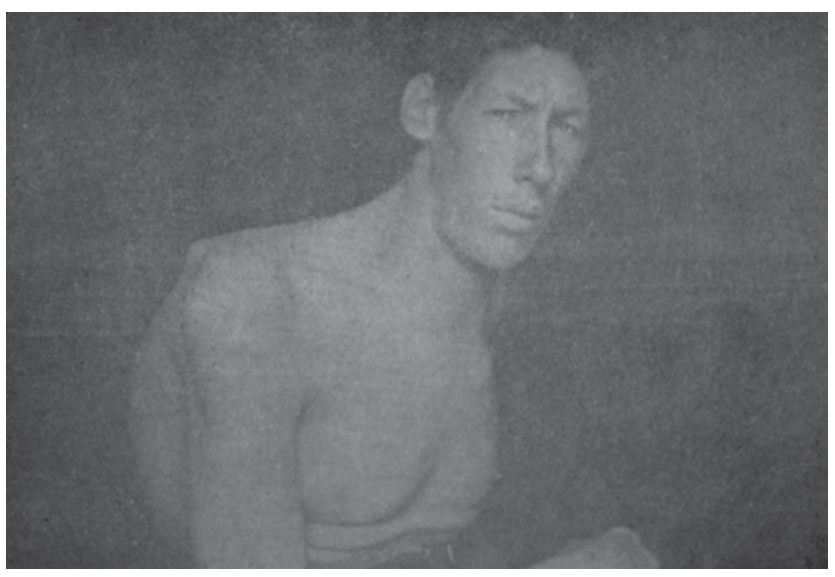

Tomado de Muñoz L., Un caso de acromegalia en Zipaquirá, Repertorios de Medicina y Cirugía 1942;2(12):150-156
Gnodde editaron un libro, Gigantism \& Acromegaly in the 20th Century ${ }^{(17)}$ en donde podemos encontrar fascinantes historias sobre pacientes con estas patologías durante el último siglo. Para los interesados en el tema, Arjen Gnodde tiene una página web (http:www. thetallestman.com) en donde se puede encontrar bastante información sobre la presencia de gigantes en otras actividades como deportes y cine, las cuales, por espacio, no se trataron en este relato. Por ejemplo, en esta página se cita al joven Asdrubal Herrera $\operatorname{Mora}^{(18)}$, el colombiano más alto en el momento, que mide 2,28 m (figura 5) y vive en Armenia y a quien conocí personalmente, ya que su médico tratante durante un tiempo fue el Dr. John Jairo Duque, quien lo presentó en una reunión médica sobre acromegalia hace ya algunos años.

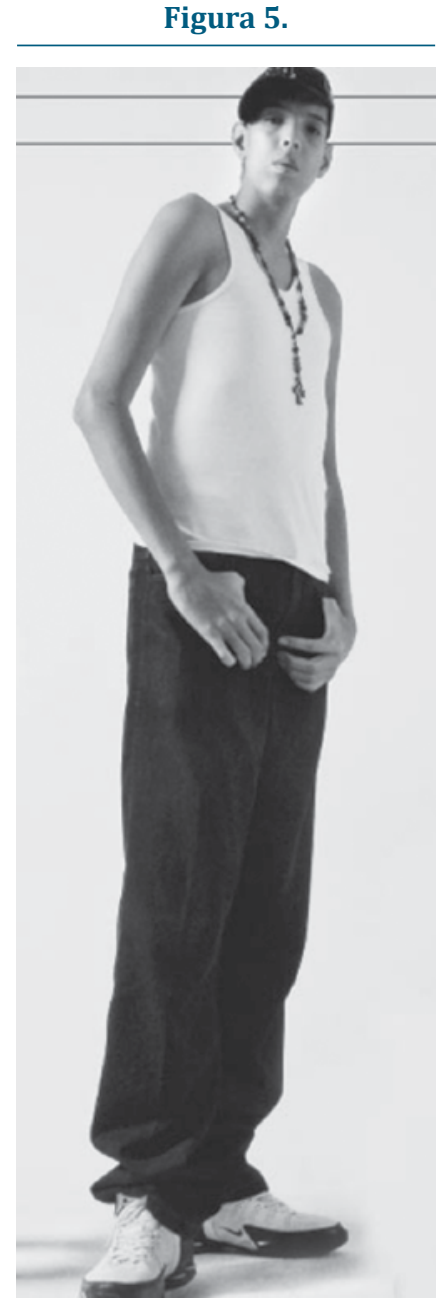

Tomado de internet: http// www.thetallestman.com/asdrubalherreramora el día 29 de sep 2015

\section{Referencias}

1. Mitchell S, Conversations, Return of Gilgamesh, Archaeology 2005;58 (3):128.

2. Hoedl S, The disease of Akhenaton . Int J Dermatology 1989; 28(3):201-203.

3. Langebaeck Carl Henrick, Los Herederos del Pasado, Indigenas y pendamiento criollo en Colombia y Venezuela Tomo 1 Ediciones Uniandes Bogota DC., 2009 pags 105-112.

4. Charlier P, Tsigonaki C, A case of acromegaly (Greece, 7th century AD), European Journal of Endocrinology 2011; 165: 819-821.

5. Minozzi S et al, Pituitary Disease from the Past: A Rare Case of Gigantism in Skeletal Remains from the Roman Imperial Age J Clin Endocrinol Metab, 2012;97 (12):4302-4303.

6. Restrepo G, Memoria de la Historia. Historias Clínicas de la Corte de España, Ed Planeta 2000 pags 21-26.

7. Restrepo G. Memoria de la Historia. Historias Clinicas de la Corte de Francia Ed Planeta 1997 pags 94-100.

8. Login I., Login J., Governor Pio Pico, the monster of California...no more: lessons in neuroendocrinology. Pituitary 2010;13: 80-86.

9. Martino E. Endocrinology and Art Drawing of a tooth to a giant.acromegalic man J. Endocrinol. Invest. 32: 293, 2009.

10. Toni R et al Endocrinology and Art. Acromegaly and Goiter in the precolumbian mesoamerican population J. Endocrinol. Invest. 2007; 30: 169-170.

11. Faglia G., Endocrinology and Art Was Caravaggio affected with y acromegaly?.J Endocrinol Invest 2011; 34:85.

12. Pozzilli P Leslie D, Endocrinology and Art, Louise Ou La servante Bretonne J. Endocrinol. Invest. 2003; 26: 1051.

13. Guaraldi F, Vannini F., Endocrinology and Art Cubist Portrait of acromegalic woman. J Endocrinol Invest 2013; 36:544.

14. Barbosa G, Wiesner C., Garavito G., Un Caso de acromegalia en el Instituto Nacional de Radium (1935) Revista Colombiana de Cancerologia 2004; 8(2): 52-56.

15. Muñoz L., Un caso de acromegalia en Zipaquira, Repertorios de Medicina y Cirugia 1942;2(12):150-156.

16. $\mathrm{W}$ de Herder $\mathrm{W}$ Acromegaly and gigantism in the medical literature. Case descriptions in the era before and the early years after the initial publication of Pierre Marie (1886) Pituitary (2009) 12:236-244.

17. De Herder W, Perie J Gnodde A Gigantism and Acromegaly in the 20th century, Published by Ipsen Pharma Boulogne-Billacourt, France.

18. http://www.thetallestman.com/asdrubalherreramora.htm 